\title{
Banning Microplastics in Cosmetic Products in Europe: Legal Challenges
}

\author{
Esther Kentin
}

\section{Introduction}

The sources of microplastics in the oceans - and in the Mediterranean Sea-are multiple. The first campaigns raising awareness on microplastics were focussing on microbeads in cosmetic and personal care products (I will now use the terms cosmetics and cosmetic products for both categories). Microbeads were defined as solid plastic particles, and the most frequent use was for exfoliating and scrubbing purposes. Today, microplastics are also added for other reasons such as emulsifying, film forming, binding, skin conditioning and glittering. Although representing a small part of microplastics in the environment, banning microplastics in cosmetics products seemed to be a relative demarcated exercise for three reasons. First, cosmetics are a clear defined product group in most legislations. Second, it seems that microplastics can be relatively easily replaced by alternatives, although they may be more expensive. And third, only a few types of microplastics are used in cosmetic products, polyethylene particles representing 93\%, although the use of liquid synthetic polymers and new types of microplastics is increasing.

Banning microplastics from the source is more or less the only option to prevent and reduce pollution by microplastics: measures such as collection, recycling and clean up are not possible to prevent or remove microplastics from the environment. Awareness raising and education to promote the use of products without microplastics can be effective; see for example the campaign of Beat the Microbead app. But the abundance of cosmetics with microplastics and the relatively small number of products available without microplastics makes it difficult to make a significant change in real numbers. Furthermore, the majority of consumers has not

\footnotetext{
E. Kentin $(\bowtie)$

Leiden Law School, Leiden University, Leiden, The Netherlands

e-mail: e.kentin@law.leidenuniv.nl 
been reached yet. Many consumers are still unaware that microplastics are added into cosmetics and trust that regulation would prevent any harmful substance in such a product. This is especially true for EU consumers with cosmetics being regulated by the Cosmetics Regulation. Despite the Beat the Microbead campaign and other awareness initiatives, the amount of microplastics in cosmetic products is still increasing.

\section{Legal Strategies to Ban Microplastics in Cosmetic Products}

\subsection{National Regulation}

The United States (US) is the first country to ban microplastics from rinse-off cosmetic products by its Microbead-Free Waters Act [1]. The ban was concluded in 2015 and foresees a phase-out of microbeads in the coming years. A microbead is defined as 'any solid plastic particle that is less than five millimetres in size and is intended to be used to exfoliate or cleanse the human body or any part thereof'. By 1 July 2018, the manufacturing of rinse-off products with microbeads is prohibited, while the sale of those products with microbeads will be abandoned by 1 July 2019 . France is the second country that has adopted a ban on microplastics in rinse-off products, following the same definition of microbeads in the US Microbead-Free Waters Act. In Canada, UK, Taiwan, South Korea and Sweden, similar legislation is proposed, waiting for approval and adoption. It seems that the Microbead-Free Waters Act has set the standard for defining and prohibiting microplastics as all proposed bans use more or less the same definition of microbeads, while being applicable only to rinse-off cosmetic products.

Since October 2016, six countries-South Korea being the first on 6 October 2016, followed by Taiwan, Canada, France, New Zealand and Sweden-have notified the WTO TBT Committee of their proposed bans on microplastics in rinse-off cosmetics. The WTO TBT Committee was set up by the Agreement on Technical Barriers to Trade to monitor measures that set standards to product for public policy reasons, such as human health, environment, consumer information and quality. These measures are allowed under the TBT Agreement only if they are non-discriminatory and do not create any 'unnecessary obstacles to international trade'. National technical standards should follow international standards as much as possible, but if these are not available, countries may set their own standards. Countries should notify the other WTO members via the Secretariat of proposed measures and provide a reasonable time for reactions and comments. No comments of other countries have been received, but it may be too early to draw any conclusions. 


\subsection{EU Regulation}

Several EU regulations have been suggested to suit a ban on microplastics in cosmetics [2]. The Marine Strategy Framework Directive [3] is often cited as regulation that provides an obligation to prevent marine litter. The directive obliges EU Member States to develop a strategy for its marine waters and leaves it up to the Member States to adopt tools and measures. Regarding microplastics, first baselines have to be established before targets can be set [4]. France considers its proposed ban on microplastics in cosmetic products as an implementation measure under the directive. So, although the Marine Strategy Framework Directive could facilitate national measures on microplastics, it cannot provide for an EU wide ban on microplastics.

The Cosmetics Regulation [5] regulates the ingredients of products and may restrict certain substances in certain product categories. Since the regulation is based on the working of the internal market and protection of human health, a prohibition of microplastics in cosmetic products for environmental reasons would depart from its legal basis. For restricting substances for environmental considerations, the Cosmetics Regulation refers to the REACH Regulation. However, if the normal use of products with microplastics can be proven to be harmful for human health, those products can be restricted by including microplastics on the list of restricted substances by amendment.

Under the REACH Regulation [6], chemical substances are regulated to ensure a high level of protection of human health and the environment. Any new substance must be registered and evaluated and then can be authorised or restricted. However, polymers do not have to be registered under the REACH at this moment [7] ${ }^{1}$; so any existing and also new polymers are not registered and evaluated, let alone restricted. To include polymers in the REACH Regulation, the European Commission has to review the exemption using strict criteria: (1) only if a practicable and cost-efficient way is available, (2) based on sound technical and valid scientific criteria, (3) after reporting on (a) risks posed by polymers in comparison with other substances and (b) taking into account competitiveness and innovation on the one hand and the protection of human health and the environment on the other.

The Ecodesign Directive [8] is also referred to in regulating microplastics in cosmetic products, but would only be possible if it is first amended to include standards on resource efficiency. Such amendment should restrict the use of plastics or other persistent substances to minimise waste and pollution. Since the Ecodesign Directive sets standards for very specific product categories, banning microplastics in cosmetics would require multiple procedures and implementing measures. Despite these legislative hurdles, this type of regulation could force manufacturers of products containing or made of plastic to consider waste and disposal issues in the design of products.

\footnotetext{
${ }^{1}$ REACH Regulation, recital 41 and art. 3 and 138.
} 


\subsection{Voluntary Agreements}

On both national levels and regional levels, voluntary agreements have been discussed and are still being discussed. In 2015, Cosmetics Europe has advised its members 'to discontinue the use of synthetic, solid plastic particles used for exfoliating and cleansing that are non-biodegradable in the marine environment in wash-off cosmetic products placed on the market as of 2020' ${ }^{2}$ Unfortunately, this advice does not include stay-on products and liquid synthetic polymers, while a phase out of more than five years is provided. Besides, it is only an advice, and no pledge or commitment is made. The Dutch branch organisation of cosmetics manufacturers has notified that it will not actively support a voluntary agreement between manufacturers to ban microplastics as it may be in violation with European competition law.

European competition law forbids agreements between manufacturers and other market players that would restrict competition. Exceptions to this rule are possible, but only if it would improve the production of goods or lead to technical or economic progress and consumers would benefit from these improvements. The requirement that consumers have to benefit from these agreements has been interpreted strictly by the European Commission, meaning that consumers have to benefit financially. The Commission has actually been warning that even if national authorities are encouraging companies to enter into voluntary agreements for public purpose objectives, such as environmental protection, it does not mean that these agreements are permissible under EU competition law. Therefore, a voluntary standard-setting agreement between manufacturers of cosmetic products banning microplastics has to comply with strict requirements [9]. First of all, participation to the standard-setting agreements should be open to all and transparent, while compliance should be strictly voluntary. If the agreement would lead to an increase of prices, the agreement may fall under the exceptions, but it is essential that the agreement would lead to efficiency gains — read economic gains - for the consumer. Agreements regarding prices, either to stabilise or to increase, between manufacturers will violate the law and may be punished with high fines. Due to the strict interpretation of the Commission, manufacturers and trade organisations are hesitant to enter into any agreement. Therefore, it will not be easy to conclude such an agreement with manufacturers of cosmetics.

\subsection{Labelling}

There are several initiatives on labelling in Europe, either from the cosmetic industry, such as NATRUE and COSMOS, or NGOs and private parties, such as Beat the Microbead and CodeCheck. Some labels of the cosmetic industry do not

\footnotetext{
${ }^{2}$ Cosmetics Europe, recommendation on solid plastic particles. https://www.cosmeticseurope.eu/ how-we-take-action/driving-sustainable-development. Accessed 5 July 2017.
} 
state explicitly whether microplastics are permitted under their standards. For example, COSMOS permits synthetic substances within agro-ingredients up to $3 \%$. Although labelling will raise awareness and gives consumers a choice, the impact of current labels is relatively small. The market is dominated by only five conglomerates owning 127 brands, L'Oréal being the leader with 39 brands. ${ }^{3}$ Another 15 companies divide more or less the rest of the market, making up a total of roughly $70 \%$ market share of the global market for only 20 companies. $^{4}$ Since there is hardly any commitment from the branch organisations to remove microplastics from products, voluntary labelling of products concerning microplastics is not expected.

The Cosmetics Regulation requires manufacturers to place a list of ingredients on the packaging of cosmetic products. ${ }^{5}$ Microplastics could thus be identified if it would be clear - also for consumers - which substances are considered as a plastic. For nanomaterials, the term 'nano' is required to be indicated on the packaging. Such requirement could equally be proposed for plastics. However, it has to be seen whether such amendment would lead to a reduction of microplastics in cosmetic products. On national level, a mandatory labelling initiative for microplastics is pending in Italy.

\section{Conclusions and Challenges}

- The present national bans only restrict the use of microplastics in rinse-off cosmetic products, while leave-on products such as sunscreen and creams pose an equal threat to the environment.

- A limited definition of microplastics is used in national bans as well as in labelling initiatives: only solids, while liquid synthetic polymers are increasingly used.

- National bans but also EU regulation may restrict more stringent regulation. The US Microbead-Free Waters Act prohibits federal states to ban microplastics in other cosmetic products, such as leave-on, and also other phases of microplastics.

- The WTO TBT Agreement is applicable to national and regional bans of microplastics, as the restriction is a 'technical barrier to trade'. Justification has to

\footnotetext{
${ }^{3}$ Willett, M. and Gould, S.: These seven companies control almost every single beauty product you buy. Insider 18 May 2017. http://www.businessinsider.com/companies-beauty-brands-connected2017-5. Accessed 5 July 2017. The five biggest companies are as follows: L'Oréal \$27.6 billion, Unilever \$22.3 billion, Procter \& Gamble \$18 billion, Estée Lauder \$11.3 billion, Colgate-Palmolive $\$ 10.7$ billion (Beauty sales 2015 ).

${ }^{4}$ Value of the cosmetics market worldwide in 2015 was $€ 221$ billion. https://www.statista.com/ statistics/585522/global-value-cosmetics-market/. Accessed 5 July 2017. TOP 20 Global Beauty Companies: All Over the Map. http://www.beautypackaging.com/heaps/view/2941/1/232950. Accessed 5 July 2017.

${ }^{5}$ Cosmetics Regulation, art. 19.
} 
be sought in environmental protection. International standards may be used as guidelines, so setting the 'right' standards, also in voluntary agreements, is crucial.

- Banning microplastics as substances in products in the EU requires amendment of the REACH Regulation to firstly include polymers in the regulation. The European Commission should take the initiative to review the exemption of polymers in REACH and take steps accordingly to include polymers in registration and evaluation procedures.

- Voluntary agreements are restricted by EU Competition rules, and can only be concluded if they contain no obligation to comply, if they are accessible for all manufacturers, if the procedure is transparent and if products will not be more expensive for the consumer.

- Although the gains of labelling could be small, informing consumers about microplastics in cosmetic products remains essential as long as there is no ban on microplastics.

Acknowledgements The Plastic Soup Foundation commissioned legal research on microplastics to the Leiden Advocacy Project on Plastic. Research for the project was carried out and supervised by the author, with the help of students of the Leiden Advocacy Project on Plastic, in particular Clara Hurley, Judith Janssen, Ladislav Kovac, Marleen Schreuder, Isaure Simonin, Floor Veldhuis, Jingyuan Zeng and Wenbin Zhong.

\section{References}

1. H.R.1321-Microbead-Free Waters Act of 2015, 114th Congress (2015-2016). https://www. congress.gov/bill/114th-congress/house-bill/1321. Accessed 4 Jul 2017

2. Eunomia: Study to support the development of measures to combat a range of marine litter sources: Report for the European Commission DG Environment. Eunomia, Bristol 2016

3. Directive 2008/56/EC of the European Parliament and of the Council of 17 June 2008 establishing a framework for community action in the field of marine environmental policy [2008] OJ L 164/19

4. Galgani, F., et al.: Marine litter within the European Marine Strategy Framework Directive. ICES J. Mar. Sci. 70(6), 1055-1064 (2013)

5. Regulation (EC) $1223 / 2009$ of the European Parliament and of the Council of 30 November 2009 on cosmetic products (recast) [2009] OJ L342/59

6. Regulation (EC) 1907/2006 of the European Parliament and of the Council of 18 December 2006 concerning the Registration, Evaluation, Authorisation and Restriction of Chemicals (REACH), establishing a European Chemicals Agency, amending Directive 1999/45/EC and repealing Council Regulation (EEC) No 793/93 and Commission Regulation (EC) No 1488/94 as well as Council Directive 76/769/EEC and Commission Directives 91/155/EEC, 93/67/EEC, 93/105/EC and 2000/21/EC [2006] OJ L396/1

7. Vaughan, S.: EU chemical regulation: new governance, hybridity and REACH. Edward Elgar, Cheltenham (2015)

8. Directive 2009/125/EC of the European Parliament and of the Council of 21 October 2009 establishing a framework for the setting of ecodesign requirements for energy-related products [2009] OJ L285/10

9. Commission.: Guidelines on the applicability of Article 101 of the Treaty on the Functioning of the European Union to horizontal co-operation agreements' (Communication) 2011/C 11/01 